\title{
Internationalisation and student diversity: how far are the opportunity benefits being perceived and exploited?
}

\author{
Helen Spencer-Oatey ${ }^{1}$ (D) $\cdot$ Daniel Dauber ${ }^{1}$
}

Published online: 13 April 2019

(C) The Author(s) 2019

\begin{abstract}
Most schemes that rank universities for their level of internationalisation are based on compositional criteria, such as the numbers of international students and staff, and student mobility numbers. Yet if such diversity is to be meaningful beyond financial benefits and enhance the quality of education and research, including stimulating growth in (inter alia) intercultural competence, other measures are needed. Research in the intercultural field indicates that two foundational elements are required for this stimulation: (a) positive attitudes (e.g. openness and curiosity) towards diversity and motivation to learn about/engage with it and (b) experiences of difference that challenge people's viewpoints, ideas and ways of doing things. Yet these variables are rarely probed simultaneously in higher education research. This article reports a study that used a tool to probe both of these elements in combination, in relation to three facets relevant to internationalisation: social integration, academic integration and global opportunities and support. The study draws on data from 2360 students, gathered from four different countries, to explore how the opportunity benefits offered by diversity are being perceived and exploited by the respondents. The interconnections between the variables are explored, along with similarities and differences in ratings across regional groups. The article ends by discussing the conceptual and strategic planning implications of the findings.
\end{abstract}

Keywords Internationalisation - Integration · Diversity - Intercultural competence · Comfortzone · Global graduates

Helen Spencer-Oatey

helen.spencer-oatey@warwick.ac.uk

Daniel Dauber

d.dauber@warwick.ac.uk

1 Centre for Applied Linguistics, University of Warwick, Coventry CV4 7AL, UK 


\section{Introduction}

De Wit et al. (2015), in a revision of Knight's (2003, 2004) well-known definition of internationalisation, define internationalisation as follows: 'the intentional process of integrating an international, intercultural or global dimension into the purpose, functions and delivery of post-secondary education, in order to enhance the quality of education and research for all students and staff, and to make a meaningful contribution to society' (De Wit et al. 2015, p.29, emphasis in the original). They explain that they have made this adjustment in order to stress the importance of internationalisation being more inclusive and less elitist. Along similar lines, the British Council (2014, p. 4) argues that the "integration of all students is an elemental factor in the expanding concept of internationalisation not only due to immediate student outcomes of comprehensive learning and cultural awareness but also due to long term benefits for the individual, the institution and the UK'. Similarly, Hudzik (2011, p. 35) identifies 'the integration of all international students and scholars into the campus living and learning environment' as one of the key stretch goals for internationalisation.

As these authors make clear, internationalisation is not just a matter of international mobility, nor only of recruiting international students and helping them adjust. On the contrary, it concerns all students (domestic and international) and all staff (academic and professional), whatever their location and whatever their level. The authors also all emphasise the importance of 'integration' and point to its multifaceted value: for the individual, the institution and the country, and with regard to the quality of education and service to the community (within the university and beyond).

These perspectives raise a number of fundamental questions: How do students, staff and senior management perceive the opportunity benefits that diversity brings? To what extent are these opportunities being capitalised on? In this article, we focus on the students' perspectives and experiences of these issues. We report on a tool designed to examine them, the multifaceted insights that it has yielded, and the implications of the findings for all concerned.

\section{Literature review}

\section{Ranking universities for internationalisation}

Universities throughout the world are now being ranked for their level of internationalisation. The best known organisations that publish such measures (Times Higher Education (THE) rankings, QS World rankings and U-Multirank) all use parameters that focus exclusively on objectively countable characteristics, as Table 1 illustrates. We label this a compositional approach.

Clearly, compositional internationalisation is a vitally important element of the internationalisation process, as the presence of international students and opportunities to study abroad offer very valuable potential opportunities for the transformative learning that educationalists desire for their students. However, diversity is not an end in itself, but rather is merely the foundation for offering a 'global education'. Having a diverse population, i.e. compositional diversity, is an important prerequisite and in fact many universities' domestic student cohort may already be culturally diverse (e.g. socially, ethnically and religiously). However, as a recent British Council (2014) report points out, such compositional elements are insufficient in themselves: 
Table 1 Parameters for ranking internationalisation

\begin{tabular}{lccc}
\hline Parameters & \multicolumn{2}{l}{ Organisation } & \\
\cline { 2 - 4 } & THE & QS & U-Multirank \\
\hline Composition: international students & $\checkmark$ & $\checkmark$ & \\
Composition: international staff & $\checkmark$ & $\checkmark$ & $\checkmark$ \\
Incoming and outgoing student mobility & & $\checkmark$ & $\checkmark$ \\
International joint publications/research networks & $\checkmark$ & $\checkmark$ & $\checkmark$ \\
International orientation master programmes & & & $\checkmark$ \\
International doctorate degrees & & & $\checkmark$ \\
International research grants & & & $\checkmark$ \\
\hline
\end{tabular}

'While the benefits of a global campus are plentiful and well-publicised, they do not naturally arise due to the presence of international students; the distinction must be made that simply having a diverse student body does not mean the education or even the campus is global in nature. What comes as an essential part of a global education is the inclusion of international students in communities and classes. Integration of all students is an elemental factor in the expanding concept of internationalisation'. (p.4)

In other words, diversity does not in itself ensure that the benefits of a 'global education' will be achieved. We would therefore argue that compositional indicators, of the kind used in internationalisation league tables, provide a limited and potentially misleading representation of the degree of internationalisation. We maintain that when internationalisation is conceptualised as in these key papers (British Council 2014; De Wit et al. 2015; Hudzik 2011), existing measurement criteria need to be supplemented by complementary ones that probe aspects such as integration.

\section{Integration and its importance}

Despite the frequent use of the term 'integration' by many authors, in actual fact 'integration is a complex idea, which means different things to different people' (de Alcántara 1994; n.p.; for a review of the concept, see Spencer-Oatey and Dauber, in press) Within the education field, it has not always been defined in detail, but has been broadly interpreted as participation, mixing and involvement (e.g. Hou and McDowell 2014; Montgomery and McDowell 2009; Severiens and Schmidt 2009; Tinto 1998). This is also the approach taken by Rienties and his colleagues (e.g. Rienties et al. 2012; Rienties and Nolan 2014; Rienties and Tempelaar 2013) in their various studies of social and academic integration. Drawing on Tinto's (1975) work, they associate social integration with socialisation and participation in the student culture, and academic integration with persistence, arguing that adjustment is needed for both. Sometimes other terms are used with a somewhat similar meaning, including interaction (e.g. Glass and Westmont 2014), connectedness (e.g. Bethel et al. 2016), and identification (e.g. McGarvey et al. 2016); conversely, other researchers (e.g. Bennett 2004; Berry 2006; Zepke and Leach 2005) conceptualise integration (somewhat or very) differently. In this paper, we follow the many authors referred to above who use the term integration somewhat broadly to refer to the combined notion of mixing/interaction/ participation with involvement/connectedness/ identification. 
Integration (in this sense) is important in higher education (HE) for a range of reasons. Firstly, a strong social network is very valuable for personal welfare and well-being. Stress and loneliness can be a particular problem for international students (e.g. Sawir et al. 2008; Ward and Kennedy 1993) and is increasingly an issue among all students. Ward (2001) reports a number of studies that demonstrate the value of friendships, including between international and domestic students, for lowering stress, enhancing mood, improving self-esteem and for psychological well-being in general. Secondly, integration has been associated with study persistence (e.g. Tinto 1998) and academic achievement (Rienties et al. 2012). Part of this may be due to the impact of psychological well-being, but the stimulation of a wide range of ideas and viewpoints from people of different backgrounds can also be highly beneficial when circumstances are positive (e.g. Sweeney et al. 2008). Thirdly, integration and internationalisation more broadly is widely associated with the development of intercultural skills, 'global graduate' attributes and 'global citizenship'. Intercultural theorists (e.g. Anderson 1994; Kim 2001; Taylor 1994) have long argued that some kind of critical incident, obstacle or stressful situation is needed to stimulate intercultural growth, and recent qualitative research by Lilley et al. (2015) has offered empirical support for this within the HE context. They found that 'development starts with leaving the comfort zone, thinking critically about themselves and others, and engaging beyond their immediate circle' (p.231). They identify three ways in which students can stretch themselves, two of which relate to integration:

- Interpersonal encounters with diverse others

- Interpersonal relationships through friendships with people from diverse backgrounds

- Cosmopolitan role models, such as influential teachers who helped them broaden their horizons and become more 'other centred'

They argue that these conditions are the foundations or key facilitators for the development of a global mindset and growth in global citizenship qualities. ${ }^{1}$

Nevertheless, despite the importance of integration, it does not occur naturally. Intercultural theorists (e.g. Deardorff 2006; Prechtl and Davidson Lund 2009) point to the importance of being motivated to learn about/engage with cultural difference, as well as key attitudes such as openness, curiosity and respect. Unfortunately, the principle of homophily (Dunne 2009) can mitigate against such factors, acting as a negative pull.

\section{Integration, diversity and empirical research}

If integration is so important yet not automatic, we need to consider the extent to which it is being achieved. Numerous studies, quantitative (e.g. Rienties and Nolan 2014; UKCOSA 2004; Ward et al. 2005; Williams and Johnson 2011), qualitative (e.g. Brown 2009; Dunne 2009; McKenzie and Baldassar 2017) and mixed method (e.g. Spencer-Oatey et al. 2017) carried out in a range of countries (e.g. Australia, New Zealand, Ireland, the UK and the USA) have identified that generally speaking there is little mixing between domestic and international students in terms of frequency/number of friendships. In terms of students' attitudes towards integration, there is understandably a range of views (e.g. Montgomery 2010;

\footnotetext{
${ }^{1}$ Lilley et al. (2015, p. 241) identify the following broad markers for the global citizen: 'leaves comfort zone', 'thinks differently', 'engages beyond immediate circle of peers, family and friends', 'shows a mature attitude and initiative' and 'considers self, life, others, career and the world beyond narrow expectations'.
} 
Sweeney et al. 2008), although survey studies tend to report just mean figures. Moreover, many studies, especially at the national level (e.g. Australian Government Department of Education and Training 2016; Generosa et al. 2013) and including those that use i-graduate's International Student Barometer/Student Barometer use level of satisfaction as their measure, which, as explained below in the methodology section, only provides a partial picture.

Another rather surprising feature is that internationalisation research frequently focuses either on domestic students (e.g. British Council 2014; Higher Education Policy Institute 2015; National Union of Students 2017; Neves and Hillman 2018) or else on international students (e.g. Fink et al. 2007; Generosa et al. 2013; Universities UK International Unit 2015, 2016), but rarely on both together. Yet some of the rare studies that have simultaneously researched international and domestic students have reported some interesting findings. For example, Rienties and Tempelaar (2013) state that European, Latin American and Middle Eastern students reported similar levels of integration to domestic Dutch students, while 'students from Southern Asia and in particular Confucian Asia score significantly lower on academic and social adjustment' (p. 198). Clearly, it is important to move beyond the binary distinction between home and international students.

So, despite the plethora of studies on internationalisation and integration in particular, there are still several limitations to the picture we can build from them, for the following reasons:

- International and domestic students are rarely researched together and asked the same questions about their experiences relating to diversity.

- In surveys of international students, they are typically treated as a single group, with no differentiation for country or region.

- In surveys, frequently, only mean percentage figures are reported (e.g. $76 \%$ are satisfied with host friendships), with little indication of the range of viewpoints.

- Much research into integration is limited to people's satisfaction with/experience of mixed nationality friendships and group work and does not explore other aspects.

- Despite the emphasis in many university strategies on developing 'global graduates/global citizens', few studies explore students' attitudes towards this objective or the support they receive in relation to it.

To take a first step in addressing these current limitations, we devised a tool and ran a study to gain some initial insights.

\section{Methodology}

The findings reported in this article were gathered via a specially designed online questionnaire. The following sections outline and explain the methodological approach in detail.

\section{Design of the tool}

The Global Education Profiler (GEP) is a needs analysis/diagnostic tool that probes students' global education viewpoints and experiences. It was designed by combining (a) conceptual insights from the field, (b) existing research into people's experiences of internationalisation (as reviewed above, plus additional studies such as Jones 2010; Spencer-Oatey and Dauber 2015) and (c) research into the competencies required by employers (e.g. British Council 2013; Diamond et al. 2011). 
The GEP probes a number of different facets relevant to cultural diversity and the development of intercultural competence: social integration, academic integration, communication skills, foreign language skills and global opportunities and support. It does not aim at measuring any levels of intercultural competence, but rather provides systematic insights into students' perceptions of the opportunity benefits and experiences associated with diversity and the development of intercultural competence. In this paper, we focus on three constructs: social integration, academic integration and global opportunities and support.

Social integration (SI) probes the amount of interaction and social cohesion across people from diverse backgrounds. This important measure provides insights into students' nonacademic life, which can have a substantial bearing on their general well-being, which in turn can also influence their academic performance. It is not limited to friendship frequencies, as in many studies. Items used to measure SI include:

- I have good opportunities to socialise with people from many different cultural backgrounds.

- I regularly take part in events that bring students together from diverse cultural backgrounds.

Academic integration (AI) probes the interaction and cohesion of students from diverse backgrounds within classrooms and courses, as well as with academic and support staff in the department. This is crucial in nurturing students' professional growth and provides the foundation for the development of global graduate skills. It is not limited to diverse group work, as in many studies. This construct was measured using items such as:

- I have good opportunities on my course to meet people from many different cultural backgrounds.

- Academic staff encourage me to contribute relevant examples from my background experience in class discussions.

Global opportunities and support (GOS) probes two interconnected facets: (a) the opportunities available to students, such as volunteering, work experience and study abroad, which help stimulate intercultural growth through encouraging engagement with difference and (b) the explanations and support provided by the university for understanding and fostering intercultural skills. GOS was captured in the questionnaire with items such as:

- There are good opportunities to participate in volunteer activities during my course.

- People have explained to me what 'intercultural skills' are and why they are important for my future.

- My experiences on my course are helping me develop the intercultural skills needed for working in global contexts.

- Teaching staff help me in developing the intercultural skills I need to work in a global context.

There are ten items per construct and respondents rate each of the component items on 6-point Likert scales in two ways: 'Importance to me' and 'My actual experience', thereby addressing three important questions that every internationalising higher education institution (HEI) needs to keep in mind at all times: 
(1) What is important to students?

(2) How far do students experience what is important to them?

(3) How big a gap is there between what they value and what they experience?

The sequence in which the items appear within any one construct is randomised for each participant, and people are asked to rate each of them on two 6-point Likert scales. At the end of each construct section, respondents are given the opportunity to add any open comments if they wish.

The importance scale (IMP) reveals what is important to students - both the importance of the constructs (e.g. SI and AI) and the individual items that are particularly important to them. The higher the importance scores are, the greater the students' aspirations are for a global education experience. As explained above, this attitudinal element is an important prerequisite for personal growth.

The experience scale (EXP) reveals what respondents feel they are actually experiencing with respect to each of the five constructs. As also explained above, experiences of difference are the other important foundation for personal growth. High diversity experience scores are another indicator of an enriching context. The higher the experience scores are, the greater are students' opportunities for/engagement with aglobal education experience

Reliability scores were obtained for each scale (IMP and EXP) for all constructs, and all were extremely high (Cronbach's $\alpha>0.85$ ). In addition, confirmatory factor analysis was performed separately for each of the IMP and EXP scales for each construct, which further corroborated the stability of the chosen constructs $\left(\operatorname{RMSEA}_{\mathrm{IMP}}=0.06, \mathrm{RMSEA}_{\mathrm{EXP}}=0.06\right)$.

Naturally, the results from the GEP can be reported as mean scores (per construct and/or per item), but another helpful way is to display them on a matrix. When the two scales (IMP and EXP) are combined, with cut-off points halfway on each scale, they yield four quadrants that provide an overview picture of the diversity engagement context. When people's IMP and EXP scores are both high, this is the most positive situation and so this quadrant is labelled 'flourishing'. When people's IMP scores are high but the EXP scores are low, this is a problematic situation because of the failure to meet people's expectations/desires, and so this quadrant is labelled 'unfulfilling'. When people's IMP scores are low but EXP scores are high, the context is positive in terms of actual experiences, but people's aspirations are low. This quadrant is labelled 'nurturing'. The fourth quadrant is the most problematic in terms of developing 'global graduates' because students not only attach low levels of importance to it but also experience it very little. This quadrant is labelled 'limiting'. Figure 1 illustrates these different perceptual contexts. In our analyses, chi-squared tests with Yates' continuity correction were used to probe the statistical significance of differences within each quadrant of participants' IMP and EXP ratings.

It is important to mention that these are different measures from student satisfaction. Participants are not asked to rate the quality of the experience, but 'how much/little' they experience certain aspects of their university life. Thus, conceptually, these scales are different from commonly used Likert-scales which ask participants to rate their satisfaction with different aspects of their campus life. However, by combining the IMP and EXP scores it is possible to gain insights into their level of satisfaction, but with a more differentiated perspective into the bases of their ratings. This is because if satisfaction is high, it is actually unclear whether their satisfaction is because they regard the particular feature as important and are genuinely experiencing it (and would fall into the flourishing quadrant) or because they do not care about whether they experience it or not (and thus fall into the limiting quadrant). In 
Fig. 1 The Global Education Profiler's (GEP) four quadrants

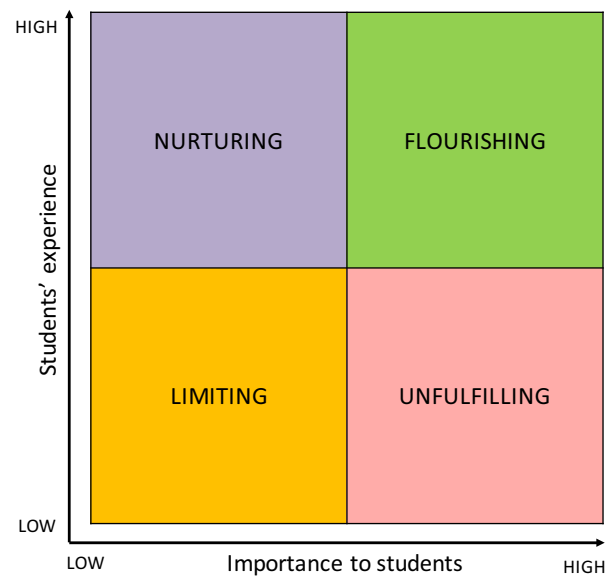

other words, with a satisfaction scale, it is not possible to interpret the reasons for such satisfaction. In the worst case scenario, a university might have perfectly satisfied students who have no aspirations whatsoever to engage with internationalisation and diversity on campus.

The GEP was used to explore the following research questions:

RQ1: What are the interconnections between the importance (IMP) that students attach to SI, $\mathrm{AI}$ and GOS and their experiences (EXP) of them?

RQ2: What similarities and differences are there in these perceptions among students from different regions of the world?

\section{The participants}

The GEP was completed online by domestic and international students at six English-speaking universities. Three of these were in the UK, one was in the Republic of Ireland, one in Belgium and one in Germany. Five of the institutions were traditional universities with strong academic reputations; the sixth one was an applied technical university. For the analysis reported in this paper, three regional groupings of student origins that were the most frequent in the dataset are focused on: domestic, European Economic Area (EEA) and Asian. Domestic students were defined as students reporting their nationality to be the same as the country in which their university was located, e.g. students of Belgian nationality at a Belgian university were classified as domestic, while students of Belgian nationality at a UK university were classified as EEA. Similarly, students of British nationality at a UK university were classified as domestic, while students of British nationality at a European university were classified as EEA. Asian students are defined by their nationality and classified as 'Asian' using the UN Country Classification System (United Nations 2018). ${ }^{2}$ This resulted in a sample size of 2360 students who completed the survey in full. Of these, 1455 were domestic students, 265 were EEA students and 640 were Asian students. Given Rienties and Tempelaar's (2013) findings

\footnotetext{
${ }^{2}$ The UN's (2018) classification of Asia includes the countries of Central Asia (e.g. Kazakhstan), Eastern Asia (e.g. China), Southeastern Asia (e.g. Malaysia), Southern Asia (e.g. India) and Western Asia (e.g. Jordan).
} 
on the impact of geographical region of origin, we wanted to move beyond a binary split of home/international. However, the characteristics of the sample prevented any meaningful statistical analyses based on national groups alone. So, the rationale for creating these three clusters is largely for statistical reasons. These were the largest student cohorts in the sample, and the number of respondents which were not covered by these three clusters was marginal and statistically not useful. See Table 2 for the demographic characteristics of the participant sample.

Due to growing concerns regarding 'survey fatigue' of students, gaining full access to a large number of HEIs for research purposes has become extremely difficult in certain areas of Europe. For the purpose of this study, it was not possible to collect data from entire institutions. Instead, participating institutions chose which students to invite, for example by cohort year or by faculty. Subsequently, all students were emailed by their respective institutions to participate in the study. Thus, the presented data reflects a diverse data set from different institutions and different student populations.

\section{Findings}

Data was analysed using the programme R V.1.1.383 and the commonly used statistical packages 'psych' as well as 'effsize' to compute the reported statistics.

\section{Interconnections between IMP and EXP}

Pearson correlations between IMP and EXP were carried out for each of the constructs (see Table 3).

As can be seen, a significant positive correlation emerged for all of them, which in almost all cases was moderate. However, for the Asian respondents, the correlation was noticeably weaker for GOS.

While the two scales are clearly thematically linked, further tests showed some significant differences. Paired sample tests were conducted on the IMP and EXP scores for each construct and they all came out as significantly different (based on Wilcoxon, $p<0.001$ for all constructs). Moreover, as demonstrated by the findings reported below for each construct, these overall findings mask a noticeable amount of individual variation in the IMP/EXP interconnections, limiting insights for strategic planning purposes unless unpacked more fully.

The results obtained for each of the constructs are presented in turn below.

Table 2 Demographic characteristics of the participant sample

\begin{tabular}{llll}
\hline & Domestic & EEA & Asia \\
\hline Nationality (top 3 most frequent) & UK & Germany & China \\
& Belgium & France & Malaysia \\
& Ireland & Italy & $44 / 55 \%$ \\
Gender (M/F) & $44 / 55 \%$ & $51 / 48 \%$ & $23 / 22$ \\
Age (mean/median) & $22 / 20$ & $22 / 21$ & $52 \%$ \\
Level of study & & & $46 \%$ \\
- UG & $87 \%$ & $76 \%$ & $2 \%$ \\
- PGT & $9 \%$ & $18 \%$ & $6 \%$ \\
\hline
\end{tabular}


Table 3 Pearson correlations of IMP and EXP scores for SI, AI and GOS (all correlations are significant at $p<0.01)$

\begin{tabular}{lllll}
\hline & Overall & Domestic & EEA & Asia \\
\hline SI & 0.468 & 0.464 & 0.460 & 0.410 \\
AI & 0.457 & 0.478 & 0.442 & 0.413 \\
GOS & 0.447 & 0.431 & 0.468 & 0.284 \\
\hline
\end{tabular}

\section{Social integration}

The mean scores for SI, overall and by region, are shown in Table 4.

Figures 2, 3 and 4 show the spread of results according to region of origin and, as can be seen from the scatterplots, there is a wide range of different viewpoints and experiences, both within and across regional groups. Table 5 gives the percentage of respondents attributing importance (or great importance) to SI as well as the percentage of those who are experiencing it to a high or very high degree. This Table 5 data, in conjunction with the scatterplots, shows that the majority of students, whatever their region of origin, attributed importance or great importance to SI, but that the percentage was much lower for domestic students $(67 \%)$ than for EEA and Asian students (both 86\%).

When comparing ratings of experience with ratings of importance, Table 5 also shows that the proportions of students experiencing high or very high levels of SI was lower than the proportions attaching importance to it, especially for Asian students. This difference in IMP/ EXP ratings was statistically significant for each of the three groups (domestic $X^{2}=146.27$, $p<0.001$; EEA $X^{2}=12.075, p<0.001$; Asian $X^{2}=49.812, p<0.001$ ). Moreover, the proportion of students experiencing high or very high levels of SI was particularly low for domestic students. Looking at it from the converse perspective, 25\% of EEA students and 37\% of Asian students reported little experience of mixing socially with people from different backgrounds, and for domestic students, this was as high as $48 \%$. At the same time, as can be seen from Figs. 2, 3 and 4, 24\% of domestic students fell into the limiting quadrant (i.e. they experienced low SI, and also felt it was not important to be socially embedded into the university community), compared with only $7 \%$ for EEA students and $11 \%$ for Asian students.

The positive aspect of these findings is that overall, all three groups attributed importance to social mixing. Nevertheless, the low experiential levels indicate that SI is an important issue that universities need to address, especially in relation to domestic students.

\section{Academic integration}

The mean scores for AI, overall and by region, are shown in Table 6 .

Figures 5, 6 and 7 show the spread of results according to region of origin and, as can be seen from the scatterplots, once again there is a wide range of different viewpoints and

Table 4 Mean scores for SI, overall and by regional cluster

\begin{tabular}{llllr}
\hline & Overall & Domestic & EEA & Asia \\
\hline Importance & 4.11 & 3.89 & 4.50 & 4.49 \\
Experience & 3.70 & 3.59 & 4.13 & 3.81 \\
\hline
\end{tabular}




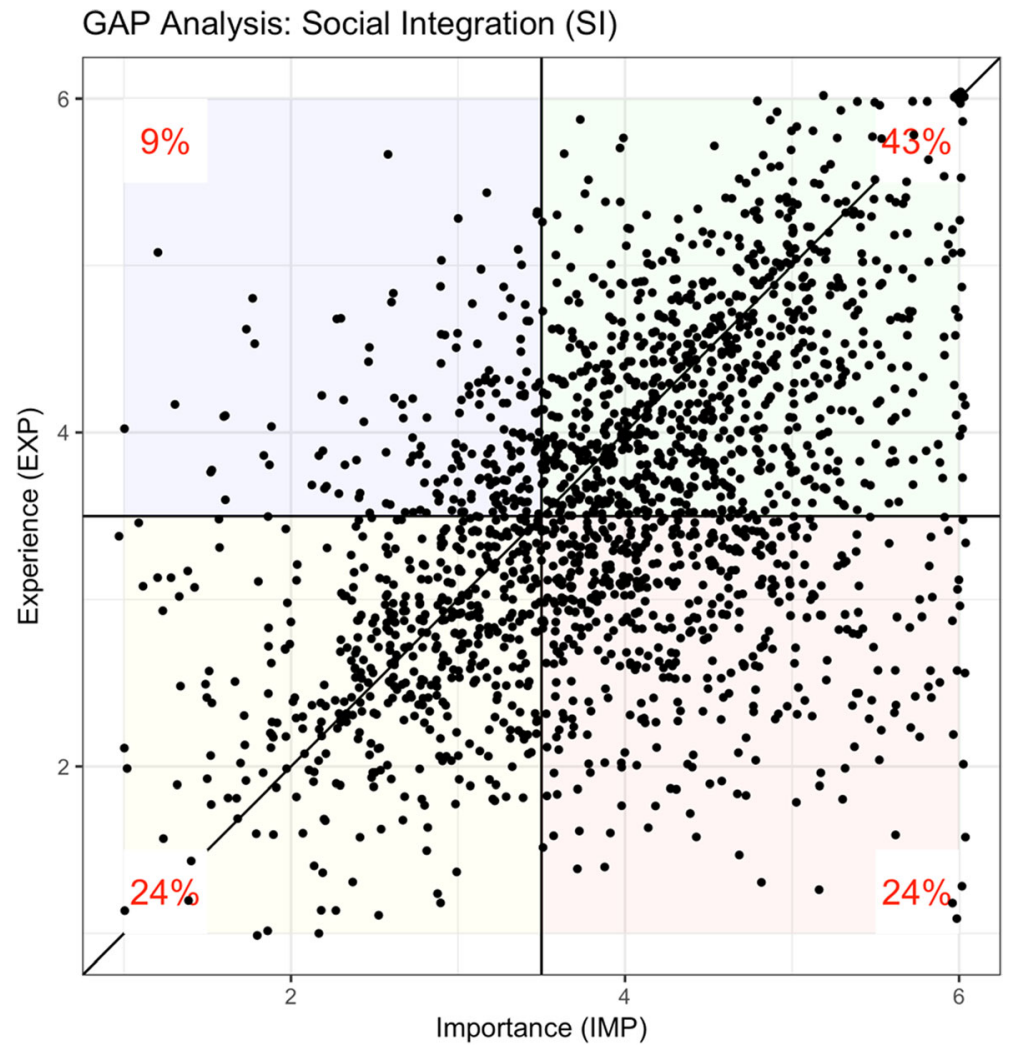

Fig. 2 Domestic students: scatterplot of participant ratings for SI

experiences, both within and across regional groups. Table 7 gives the percentage of respondents attributing importance (or great importance) to AI as well as the percentage of those who are experiencing it to a high or very high degree. This Table 7 data, in conjunction with the scatterplots, shows that the majority of students, whatever their region of origin, attributed importance or great importance to AI, but that once again the percentage was very much lower for domestic students than for EEA and Asian students.

When comparing ratings of experience with ratings of importance, Table 7 also shows that the proportions of students experiencing high or very high levels of AI was lower than the proportions attaching importance to it. While the importance scores were relatively high (ranging from $65 \%$ to $89 \%$ ), the experience scores fell below this (ranging from 53 to 74\%). This difference in IMP/EXP ratings was statistically significant for each of the three groups (domestic $X^{2}=140.43, p<0.001$; EEA $X^{2}=13.14, p<0.001$; Asian $X^{2}=44.9$, $p<0.001$ ). Moreover, the proportion of students experiencing high or very high levels of AI was particularly low for domestic students. Looking at it from the converse perspective, $26 \%$ of EEA and $30 \%$ of Asian students reported little experience of mixing academically with people from different backgrounds, and for domestic students this was as high as $47 \%$. At the same time, as can be seen from Fig. 5, 24\% of domestic students fell into the limiting quadrant (i.e. they experienced low AI, and also felt it was not important to be academically embedded into the university community). This was much less the case for international students from EEA and Asia (Figs. 6 and 7), where only $8 \%$ of students reported these attitudes. 


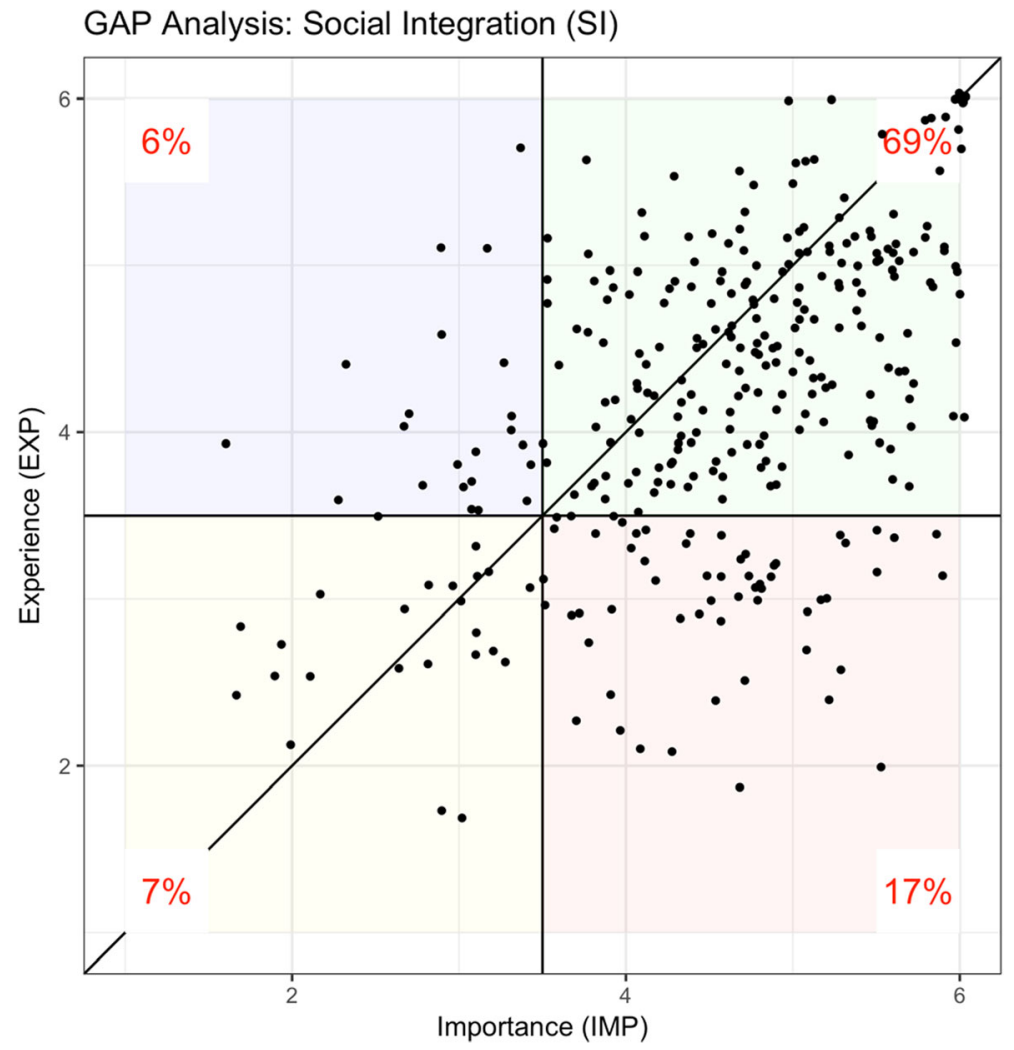

Fig. 3 EEA students: scatterplot of participant ratings for SI

All these findings indicate that $\mathrm{AI}$ is an important issue that universities need to address.

\section{Global opportunities and support}

The mean score for GOS, overall and by region, are shown in Table 8.

Figures 8, 9 and 10 show the spread of results according to region of origin and, as can be seen from the scatterplots, there is once again a wide range of different viewpoints and experiences, both within and across regional groups. Table 9 gives the percentage of respondents attributing importance (or great importance) to GOS as well as the percentage of those who are experiencing it to a high or very high degree. This Table 9 data, in conjunction with the scatterplots, shows that the majority of students, whatever their region of origin, attributed importance or great importance to GOS. The proportion was particularly high for Asian students and that for domestic students was very much lower than for both EEA and Asian students.

When comparing ratings of experience with ratings of importance, Table 9 also shows that the proportions of students experiencing high or very high levels of GOS was very much lower than the proportions attaching importance to it. Once again, this difference in IMP/EXP ratings was statistically significant for each of the three groups (domestic $X^{2}=140.74, p<0.001$; EEA $X^{2}=20.966, p<0.001$; Asian $X^{2}=31.062, p<0.001$ ). Moreover, the proportion of students 


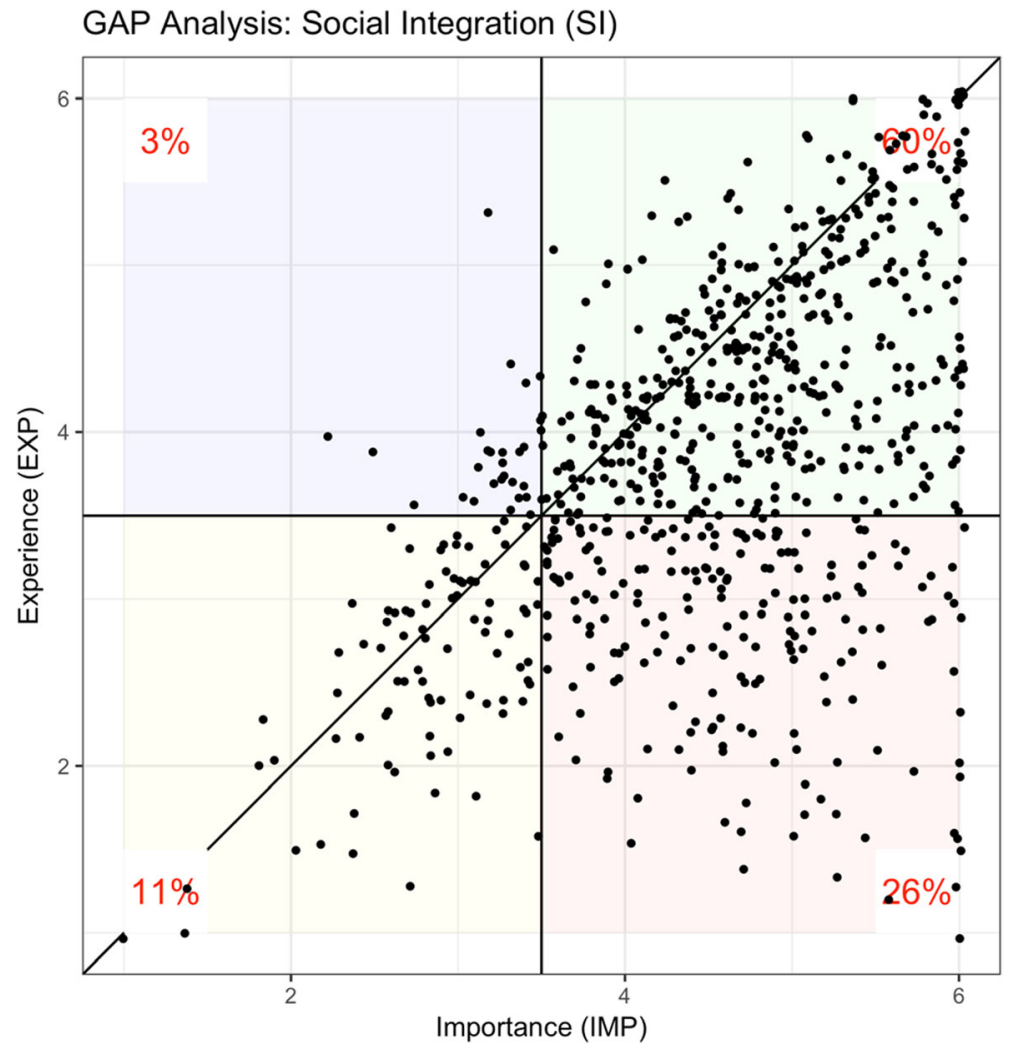

Fig. 4 Asian students: scatterplot of participant ratings for SI

experiencing high or very high levels of GOS was particularly low for domestic students. Looking at it from the converse perspective, overall, almost half of all the students in the dataset reported that they had little or no experience in this area. While 39\% of Asian students and $43 \%$ of EEA students gave low ratings for their experience of GOS, more than half of the domestic students $(58 \%)$ reported such low levels. Perhaps even more worrying, $27 \%$ of domestic students regarded this area as having little relevance for personal development, compared with 14\% for EEA students and 7\% for Asian students (see Figs. 8, 9 and 10). All these findings indicate that global opportunities development is an important issue that universities need to address.

Table 5 Percentage of respondents attributing importance/great importance to SI and the percentage who reported high/very high experiences of it

SI rated as important or very important (flourishing + unfulfilling)
High or very high levels of SI experience (flourishing + nurturing)

\begin{tabular}{lll}
\hline Domestic students & $67 \%$ & $52 \%$ \\
EEA students & $86 \%$ & $75 \%$ \\
Asian students & $86 \%$ & $63 \%$ \\
\hline
\end{tabular}


Table 6 Mean scores for AI, overall and by regional cluster

\begin{tabular}{llllr}
\hline & Overall & Domestic & EEA & Asia \\
\hline Importance & 4.11 & 3.82 & 4.46 & 4.62 \\
Experience & 3.76 & 3.59 & 4.06 & 4.00 \\
\hline
\end{tabular}

\section{Summary of findings}

In terms of our research questions, these findings can be summarised as follows:

RQ1: What are the interconnections between the importance that students attach to SI, AI and GOS and their experiences of them?

- The majority of students regard the various facets of internationalisation as important or very important to them (i.e. their ratings fell within the flourishing or unfulfilling quadrants, but there is a consistent, statistically significant gap between their IMP and EXP ratings).

- The scatterplots show that, while there is a broadly positive correlation between IMP and EXP, there is also considerable variation from it.

GAP Analysis: Academic Integration (AI)

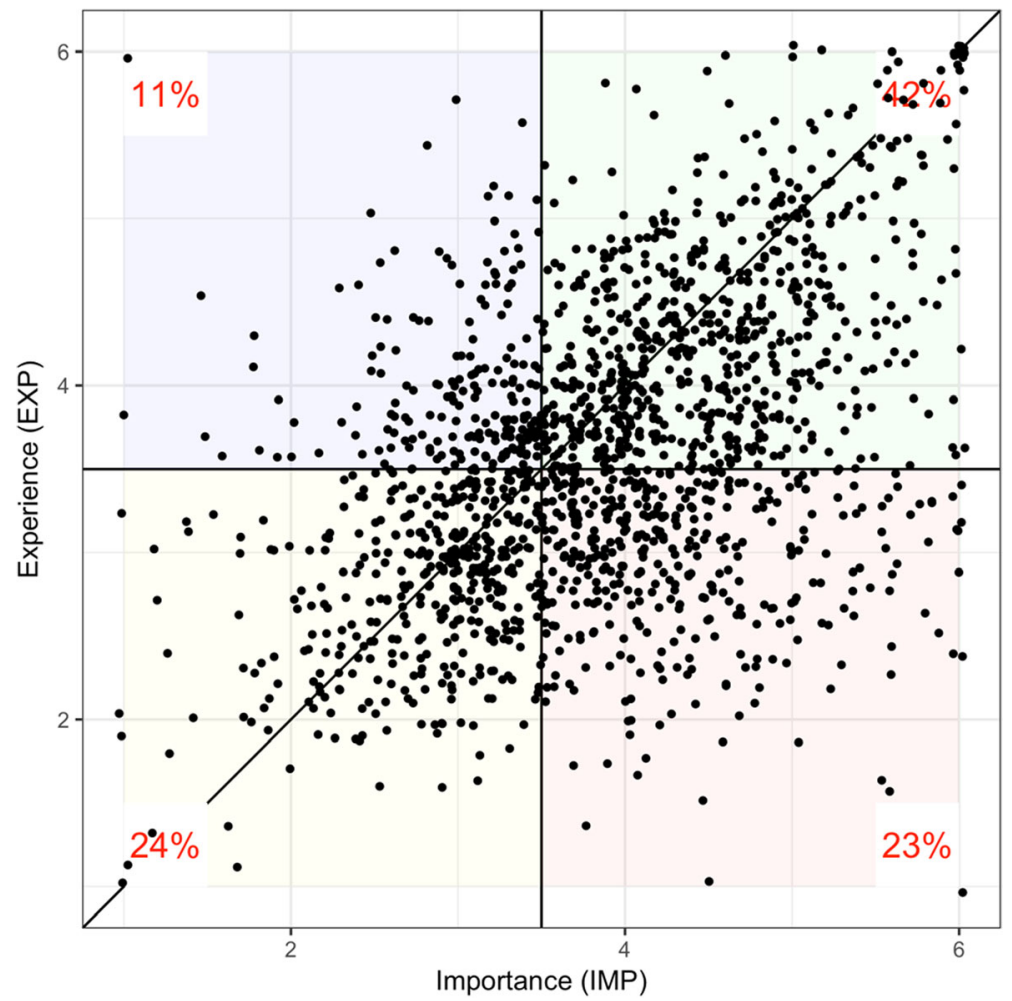

Fig. 5 Domestic students: scatterplot of participant ratings for AI 


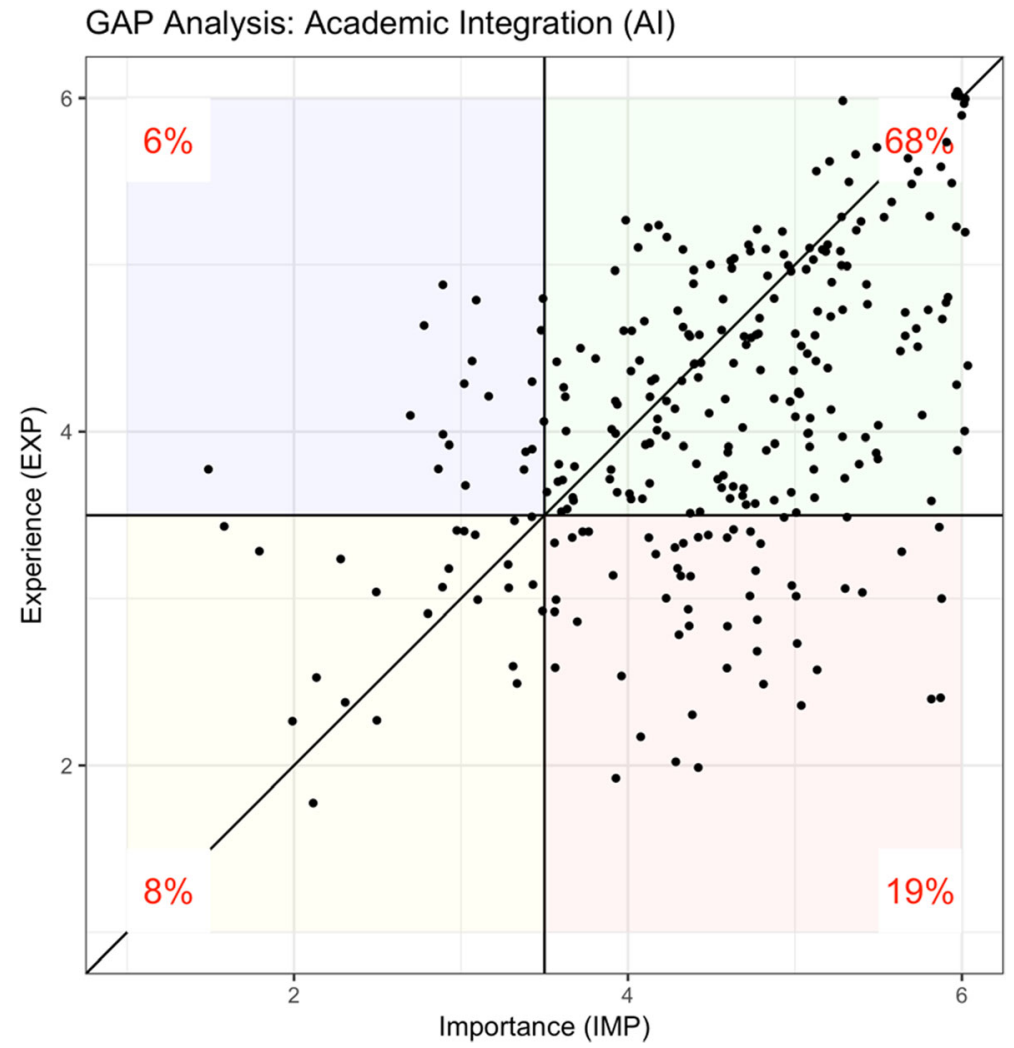

Fig. 6 EEA students: scatterplot of participant ratings for AI

- This variation is particularly noticeable for GOS.

RQ2: What similarities and differences are there in these perceptions among students from different regions of the world?

- Asian students overall attach the highest levels of importance to the various facets and reported the biggest gaps between IMP and EXP ratings.

- Domestic students overall consistently attach lower importance and lower levels of experience to the various facets than other students.

- For students from all regions, the biggest gaps between IMP and EXP are for GOS.

\section{Discussion and policy implications}

\section{The importance of measuring both IMP and EXP together}

As reported in the literature review, intercultural theory and research indicate that there are two foundational elements needed to stimulate the development of intercultural competence: (a) positive attitudes (e.g. openness and curiosity) towards diversity and motivation to learn about/ engage with it and (b) experiences of difference that take people out of their comfort zones and 


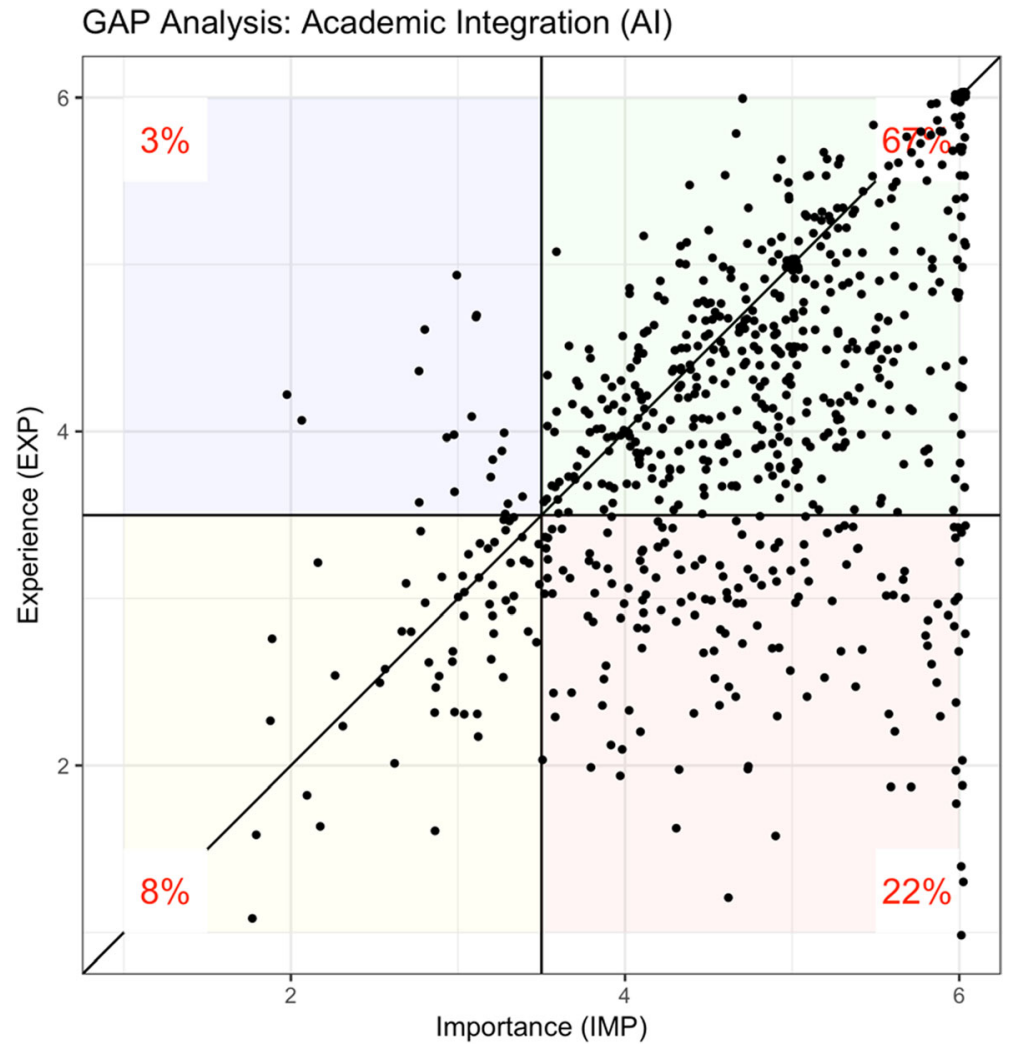

Fig. 7 Asian students: scatterplot of participant ratings for AI

stimulate new thinking and behaviour. Up to now, as also reported in the literature review, very few studies have measured both elements in the same study. Sometimes they are not differentiated, as in satisfaction surveys; sometimes only one element (especially EXP aspects) is probed. This study has shown that measuring both elements is important. While there is a broad positive correlation between the two, the correlation is not always strong (for example, GOS for Asian students) and there is a consistent statistically significant difference between IMP and EXP ratings. The scatterplots show that many respondents' ratings fall quite a long way (or a very long way) from the diagonal (i.e. the diagonal is where IMP and EXP scores are the same and indicate satisfaction). Separating out the variables yields valuable information for strategic planning purposes. Students' ratings that fall close to the diagonal will emerge as satisfied in studies that use ratings of level of satisfaction, yet this includes those in the limiting

Table 7 Percentage of respondents attributing importance/great importance to AI and the percentage who reported high/very high experiences of it

AI rated as important or very important (flourishing + unfulfilling)
High or very high levels of AI experience (flourishing + nurturing)

\begin{tabular}{lll} 
Domestic students & $65 \%$ & $53 \%$ \\
EEA students & $87 \%$ & $74 \%$ \\
Asian students & $89 \%$ & $70 \%$ \\
\hline
\end{tabular}


Table 8 Mean scores for GOS, overall and by regional cluster

\begin{tabular}{llllr}
\hline & Overall & Domestic & EEA & Asia \\
\hline Importance & 4.20 & 3.87 & 4.50 & 4.75 \\
Experience & 3.45 & 3.23 & 3.72 & 3.80 \\
\hline
\end{tabular}

quadrant. These students are satisfied because the issue is not important to them. So, thought needs to be given as to whether this matters or not. If it does (and we would argue that it does matter, if the benefits of diversity are to be capitalised on), then special thought needs to be given as to how best to motivate these students. In other words, students are likely to respond differently to any developmental initiatives, activities or situations, according to the combination of their IMP and EXP perceptions. We offer the following tentative advice for the four main groupings of our matrix:

- For students in the flourishing quadrant, the focus needs to be on the routes to growth - in other words, helping these people reflect on and learn from their experiences, so that they can foster the global skills that employers are looking for.

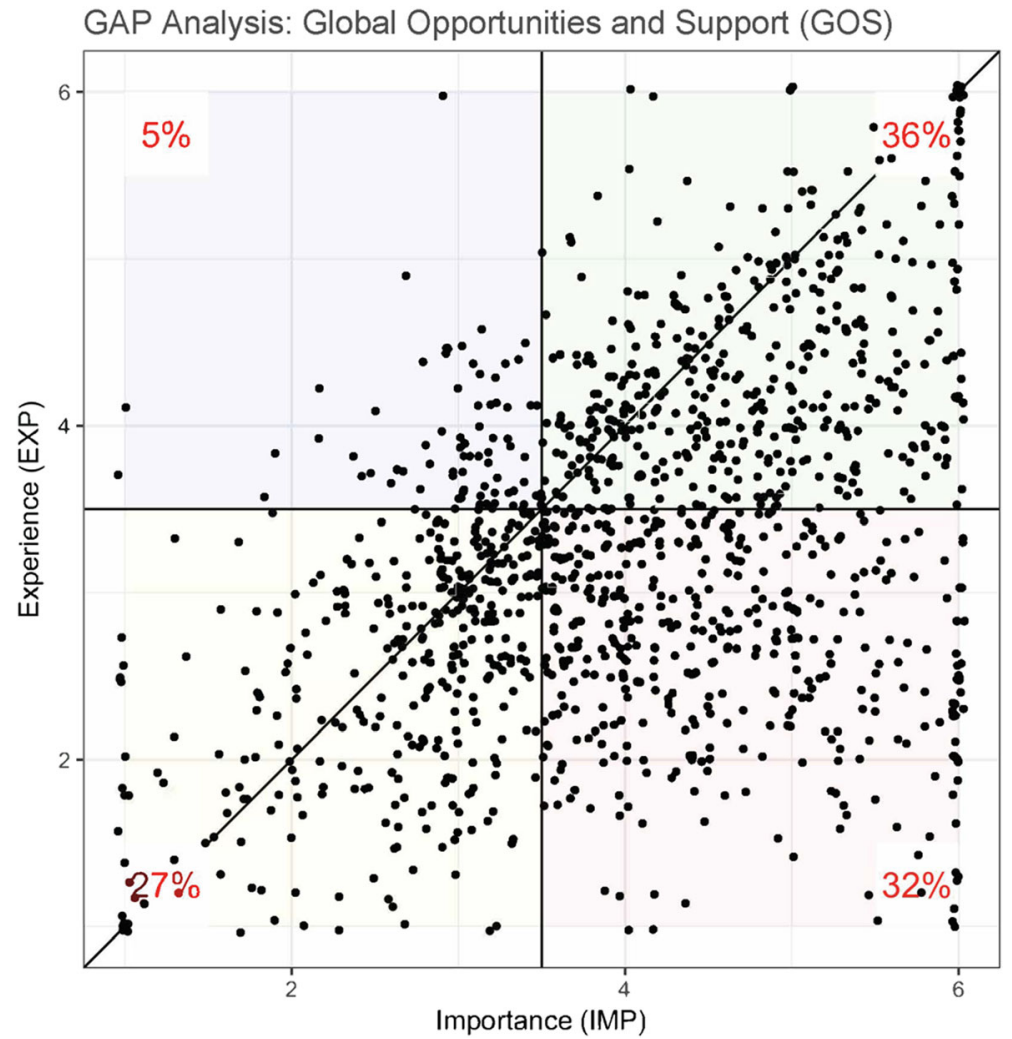

Fig. 8 Domestic students: scatterplot of participant ratings for GOS 


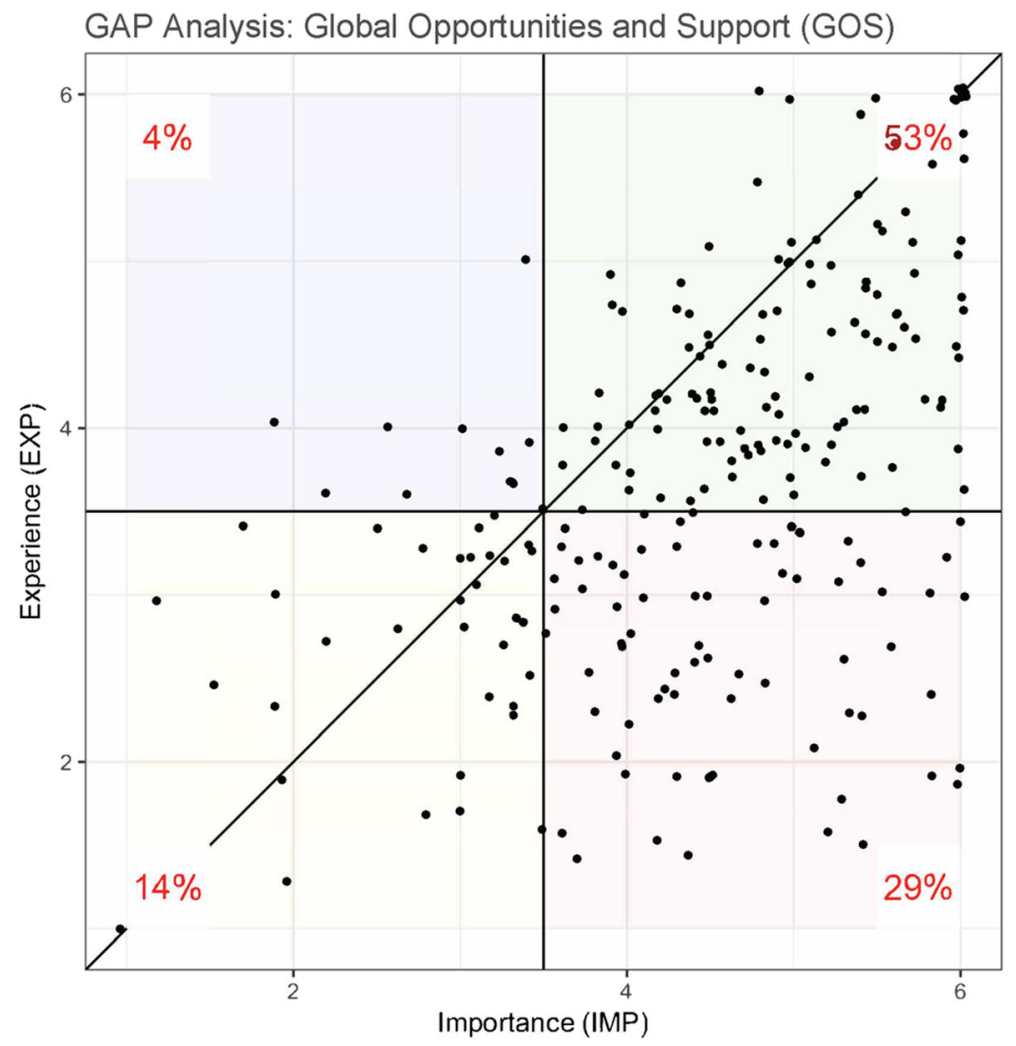

Fig. 9 EEA students: scatterplot of participant ratings for GOS

- For students in the unfulfilling quadrant, the focus needs to be on helping them gain more experiences of difference. Understanding the barriers to integration is a necessary first step; next, it will be important to help these students overcome such barriers.

- For students in the nurturing quadrant, the focus needs to be on raising their awareness of how their experiences can benefit them and, as for those in the flourishing quadrant, helping them reflect on and learn from their experiences, so that they can articulate to others the gains they are making.

- Students in the limiting quadrant are probably the most challenging group of students to deal with from an intercultural growth perspective. The first step needs to be one of gaining insights: understanding why they regard integration as unimportant as well as what barriers they face in experiencing it. Then, students need to be helped to appreciate the benefits of integration and supported in overcoming the barriers to achieving it.

\section{Reflections on the constructs of $\mathrm{SI}, \mathrm{Al}$ and GOS}

Previous research has demonstrated that integration into the university community can bring a range of benefits and that experiences of difference through moving out of one's comfort zone have particular potential for stimulating intercultural growth. 


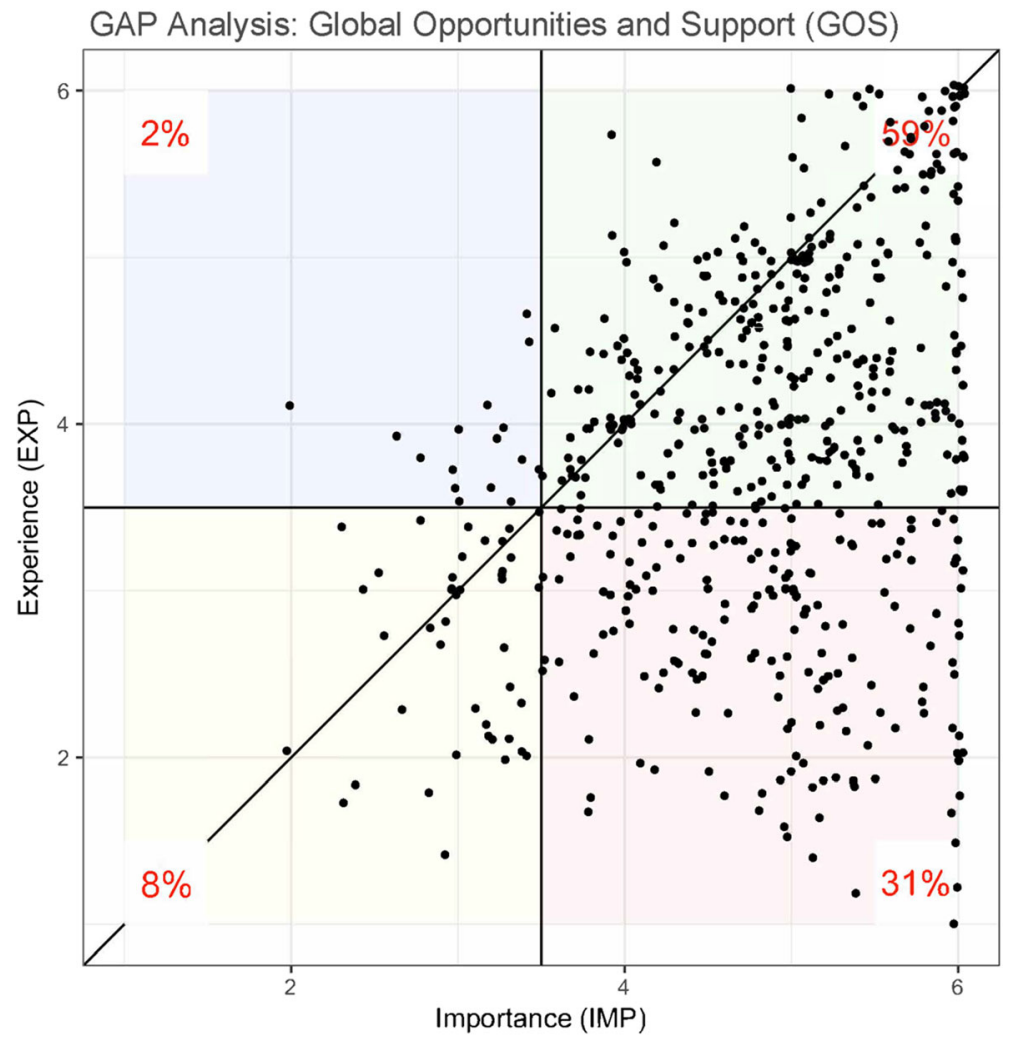

Fig. 10 Asian students: scatterplot of participant ratings for GOS

The items we used to probe SI and AI are not limited to friendship patterns and working in diverse groups as respective measures of these constructs, as has been common in much previous research. We have included a broader range, including mixing with diverse others in their accommodation and through taking part in various activities (SI) and including discussing academic topics with diverse others and feeling comfortable in participating in classroom activities (AI). Statistical tests confirmed that the ten items per facet were probing one single construct reliably.

Very often, previous research on integration has focused on mixing between domestic and international students. However, as Montgomery (2010) has pointed out, international students may perceive and experience great benefits from mixing with other international students from diverse backgrounds. This in itself can be very valuable, as it can still offer significant

Table 9 Percentage of respondents attributing importance/great importance to GOS and the percentage who reported high/very high experiences of it

GOS rated as important or very important (flourishing + unfulfilling)
High or very high experiences of GOS (flourishing + nurturing)

\begin{tabular}{lll}
\hline Domestic students & $68 \%$ & $41 \%$ \\
Other EEA students & $82 \%$ & $57 \%$ \\
Asian students & $90 \%$ & $61 \%$ \\
\hline
\end{tabular}


experiences of difference. However, this potentially leaves the domestic students with far less engagement with difference, as this study has demonstrated. While they too may experience a certain level of diversity because of in-country cultural variation, previous research (e.g. Rienties and Tempelaar 2013) indicates that it is likely to be smaller in scale and may also be of a different nature from the 'out of the comfort zone' experiences of mixing with people from very different socialisation settings. In future research, it would be helpful to dig deeper, not only at the national level, but also national internal factors such as ethnicity and socioeconomic background.

In terms of the construct GOS, it is interesting to note that the largest gaps between IMP and EXP existed here. This was particularly true of the Asian respondents, $90 \%$ of whom rated this as important or very important and only $61 \%$ of whom felt they were experiencing this, a gap of $29 \%$ (see Table 9). However, even though domestic students gave lower ratings, there was still a gap of $27 \%$. This indicates that this is an area where universities need to devote significant effort at improving the situation. In fact, a European project, Indicators for Mapping and Profiling Internationalisation (IMPI 2012), included several such support items in their toolbox.

\section{Internationalisation rankings—an alternative trajectory}

Throughout this paper, we have argued that compositional measures of internationalisation provide only one angle. We have argued that cultural diversity, if taken advantage of, can bring a range of benefits, and that integration can help develop one that is frequently associated with internationalisation - the development of global graduate/global citizen perspectives, skills and qualities. In view of this, we suggest that a trajectory of growth in internationalisation could be conceptualised as shown in Fig. 11.

In other words, universities could aim to move from compositional internationalisation to community internationalisation and through this help foster intercultural competence in their graduates.

\section{Limitations}

There are several limitations to the current study. Firstly, in terms of sampling, we cannot claim that the sampling is random or that respondents are representative of their particular institution.

\section{Stages of Internationalisation}

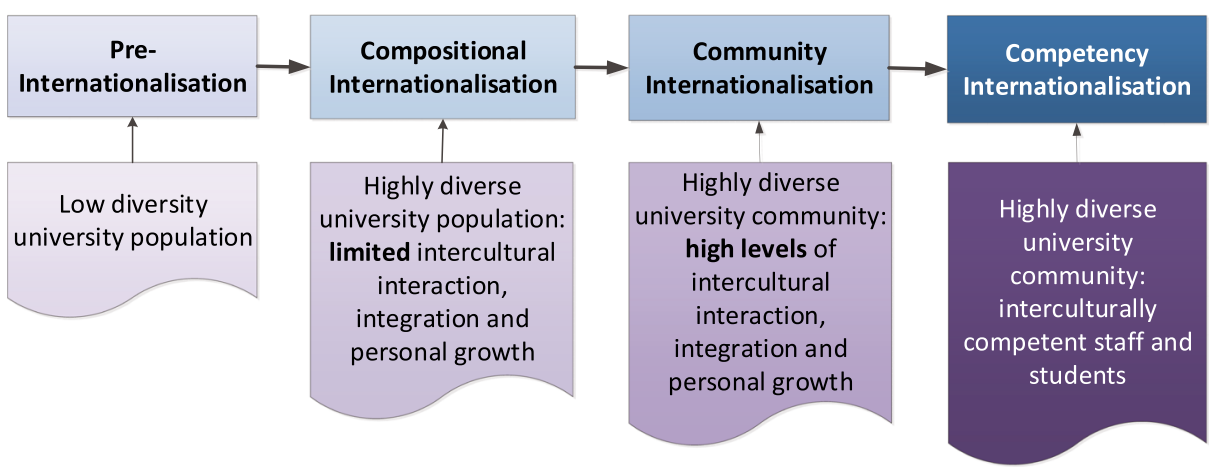

Fig. 11 Trajectory of growth in internationalisation 
This is a problem that is inherent in voluntary survey completion, within the broader context of student survey fatigue. Nevertheless, we would still maintain that the study offers systematic insights into students' attitudes towards cultural diversity and their experiences of it. By drawing on so many different institutions, it was possible to limit the statistical effect of particular contextual factors on the final outcomes.

Secondly, although the number of respondents was comparatively large, it was not large enough to conduct meaningful statistical analyses by nationality (rather than by region) or even by other major regions (e.g. Africa and the Americas). It would be interesting in the future not only to explore the impact of nationality and/or of other regions but also to be able to probe the impact of size of national cohort on people's attitudes and experiences. An even larger dataset would hopefully facilitate that and also allow systematic investigation of other variables, including level of study (undergraduate, postgraduate taught, postgraduate research), field of study (e.g. social sciences/humanities and physical/medical sciences), ethnic background and socio-economic background. Moreover, the latter data (i.e. ethnicity and socio-economic background) would also allow us to probe how the constructs interrelate with perceptions of equal opportunities.

Thirdly, analysing and reporting students' viewpoints and experiences is just the first step of the journey. The critical next step is to find ways of moving as many students as possible from the limiting, nurturing and unfulfilling quadrants to the flourishing quadrant. Our findings indicate that a 'one size fits all' solution will be inadequate, not least because people vary so much in terms of their IMP and EXP ratings. Nevertheless, as indicated above, the variation in itself may offer some guidelines - whether the hindrance is motivational or experiential or a mixture of the two, and hence where the primary developmental focus should be. Developmental ideas can also be checked against the features of relevant intercultural growth models (e.g. Deardorff 2006; Lilley et al. 2015; Spencer-Oatey 2018).

\section{Concluding comments}

In this article, we have acknowledged that seeking to enhance internationalisation through increasing the numbers of international students and student mobility numbers is avaluable prerequisite for enhancing the quality of education and research and for fostering students' personal growth in intercultural competence and sensitivity. However, we have argued that in themselves they are insufficient. Drawing on theorising and research in the intercultural field, we point to the importance of both attitude/motivation (IMP) and of experiences of difference (EXP) and argue that students need to perceive both positively if they are to capitalise on the benefits that diversity can offer them. We have proposed a trajectory of internationalisation that reflects this perspective. From a measurement point of view, we maintain that while IMP and EXP are thematically linked variables, they are sufficiently independent to be probed separately. Data gathered using a newly developed tool, the GEP, has demonstrated the various insights that measuring them in combination can provide. The tool can also be used for benchmarking purposes in relation to the trajectory we have proposed. Of course, a critical next step is to find ways of stimulating interest in diversity among those who care little about it and of helping everyone move forward on the journey towards greater intercultural competence. We hope that the nuanced information provided by the GEP can be one element that helps in this challenging but vital endeavour. 
Open Access This article is distributed under the terms of the Creative Commons Attribution 4.0 International License (http://creativecommons.org/licenses/by/4.0/), which permits unrestricted use, distribution, and reproduction in any medium, provided you give appropriate credit to the original author(s) and the source, provide a link to the Creative Commons license, and indicate if changes were made.

\section{References}

Anderson, L. E. (1994). A new look at an old construct: cross-cultural adaptation. International Journal of Intercultural Relations, 18(3), 293-328.

Australian Government Department of Education and Training. (2016). International Student Survey 2016, overview report: Available at: https://internationaleducation.gov.au/research/researchpapers/Documents/ED 17-0018\%20International\%20Student\%20Survey\%20HIGHER\%20 EDUCATION\%20Infographic_ACC.pdf.

Bennett, M. J. (2004). Becoming interculturally competent. In J. S. Wurzel (Ed.), Toward multiculturalism: a reader in multicultural education (2nd ed., pp. 62-77). Newton, MA: Intercultural Resource Corporation.

Berry, J. W. (2006). Contexts of acculturation. In D. L. Sam \& J. W. Berry (Eds.), The Cambridge handbook of acculturation psychology (pp. 27-42). Cambridge: CUP.

Bethel, A., Szabo, A., \& Ward, C. (2016). Parallel lives? Predicting and enhancing connectedness between international and domestic students. In D. Jindal-Snape \& B. Rienties (Eds.), Multi-dimensional transitions of international students to higher education (pp. 21-36). London: Routledge.

British Council. (2013). Culture at work. The value of intercultural skills in the workplace. London: British Council. Available at https:/www.britishcouncil.org/organisation/policy-insight-research/research/culturework-intercultural-skills-workplace [Accessed 15 April 2017].

British Council. (2014). Integration of international students - a UK perspective. London: British Council. Retrieved from https://www.britishcouncil.org/education/ihe/knowledge-centre/student-mobility/reportintegration-international-students [Accessed 30 December 2017].

Brown, L. (2009). Worlds apart: the barrier between east and west. Journal of International and Intercultural Communication, 2(3), 240-259.

de Alcántara, C. H. (1994). Social integration: approaches and issues. UNRISD briefing paper no. 1, world summit for social development. Geneva: United Nations Research Institute for Social Development (UNRISD). Available at http://www.unrisd.org/80256B3C005BCCF9/(httpAuxPages)/510920DA18B35 A6880256B65004C6A7B/\$file/bp1.pdf.

De Wit, H., Hunter, F., Howard, L., \& Egron-Polak, E. (2015). Internationalisation of higher education. Brussels: Policy Department, Directorate General for Internal Policies, European Parliament.

Deardorff, D. K. (2006). Identification and assessment of intercultural competence as a student outcome of internationalization. Journal of Studies in International Education, 10(3), 241-266.

Diamond, A., Walkley, L., Forbes, P., Hughes, T., \& Sheen, J. (2011). Global graduates. Global graduates into global leaders. Association of Graduate Recruiters (AGR), the Council for Industry and Higher Education (now NCUB) and CFE research and consulting. http://www.ncub.co.uk/reports/global-graduates-intoglobal-leaders.html [Accessed 15 April 2017].

Dunne, C. (2009). Host students' perspectives of intercultural contact in an Irish university. Journal of Studies in International Education, 13(2), 222-239.

Fink, G., Neyer, A.-K., \& Kõlling, M. (2007). Understanding cross-cultural management interaction. International Studies of Management and Organisation, 36(4), 38-60.

Generosa, A., Molano, W., Stokes, F., \& Schulze, H. (2013). The satisfaction of international students in New Zealand universitise and ITPS. . Wellington: Ministry of Education. Available at https://www. educationcounts.govt.nz/publications/international/the-satisfaction-of-international-students-in-new-zealanduniversities-and-itps.

Glass, C. R., \& Westmont, C. M. (2014). Comparative effects of belongingness on the academic success and cross-cultural interactions of domestic and international students. International Journal of Intercultural Relations, 38, 106-119.

Higher Education Policy Institute. (2015). What do home students think of studying with international students? HEPI report 76: Higher Education Academy. Retrieved from http://www.hepi.ac.uk/wpcontent/uploads/2015/06/HEApaper7_web.pdf [Accessed 30 December 2017].

Hou, J., \& McDowell, L. (2014). Learning together? Experiences on a China-U.K. articulation program in engineering. Journal of Studies in International Education, 18(3), 223-240. 
Hudzik, J. K. (2011). Comprehensive internationalization. From concept to action. Available at http://www.nafsa. org/_File/_downloads/cizn_concept_action.pdf. Washington: NAFSA, Association of International Educators.

IMPI. (2012). Indicators for mapping and profiling internationalisation, 2009-2012. Retrieved from http://www. impi-toolbox.eu/, 7 January 2019.

Jones, E. (Ed.). (2010). Internationalisation and the student voice. London: Routledge.

Kim, Y. Y. (2001). Becoming intercultural. An integrative theory of communication and cross-cultural adaptation. Thousand Oaks: Sage.

Knight, J. (2003). Updating the definition of internationalization. International Higher Education, 33(2), 2-3.

Knight, J. (2004). Internationalization remodeled: definition, approaches, and rationales. Journal of Studies in International Education, 8(1), 5-31.

Lilley, K., Barker, M., \& Harris, N. (2015). Exploring the process of global citizen learning and the student mindset. Journal of Studies in International Education, 19(3), 225-245.

McGarvey, A., Murphy, M., \& Byrne, E. (2016). Internationalisation and student identification. In D. JindalSnape \& B. Rienties (Eds.), Multi-dimensional transitions of international students to higher education (pp. 73-90). London: Routledge.

McKenzie, L., \& Baldassar, L. (2017). Missing friendships: understanding the absent relationships of local and international students at an Australian university. Higher Education, 74(4), 701-715.

Montgomery, C. (2010). Understanding the international student experience. Basingstoke: Palgrave Macmillan.

Montgomery, C., \& McDowell, L. (2009). Social networks and the international student experience: an international community of practice? Journal of Studies in International Education, 13(4), 456-466.

National Union of Students. (2017). Student perspectives on international students. NUS research into UK students' views on their international peers. (pp. 1-20). London: National Union of Students. Retrieved from https://www.nusconnect.org.uk/resources/Student-perspectives-on-international-students [21 January 2018].

Neves, J., \& Hillman, N. (2018). Student Academic Experience Survey 2018: advance HE and HEPI. Available at https://www.hepi.ac.uk/2018/06/07/2018-student-academic-experience-survey/.

Prechtl, E., \& Davidson Lund, A. (2009). Intercultural competence and assessment: perspectives from the INCA project. In H. Kotthoff \& H. Spencer-Oatey (Eds.), Handbook of intercultural communication (pp. 467490). Berlin: Mouton de Gruyter.

Rienties, B., \& Nolan, E.-M. (2014). Understanding friendship and learning networks of international and host students using longitudinal social network analysis. International Journal of Intercultural Relations, 41, $165-180$

Rienties, B., \& Tempelaar, D. (2013). The role of cultural dimensions of international and Dutch students on academic and social integration and academic performance in the Netherlands. International Journal of Intercultural Relations, 37, 188-201.

Rienties, B., Beausaert, S., Grohnert, T., Niemantsverdriet, S., \& Kommers, P. (2012). Understanding academic performance of international students: the role of ethnicity, academic and social integration. Higher Education, 63, 685-700.

Sawir, E., Marginson, S., Deumert, A., Nyland, C., \& Ramia, G. (2008). Loneliness and international students: an Australian study. Journal of Studies in International Education, 12(2), 148-180.

Severiens, S. E., \& Schmidt, H. G. (2009). Academic and social integration and study progress in problem based learning. Higher Education, 58, 59-69.

Spencer-Oatey, H. (2018). Transformative learning for social integration: overcoming the challenge of greetings. Intercultural Education, 29(2), 301-315. https://doi.org/10.1080/14675986.2018.1425828.

Spencer-Oatey, H., \& Dauber, D. (2015). How internationalised is your university? From structural indicators to an agenda for integration. UKCISA Occasional paper 09.2015. Available at https://www.ukcisa.org. uk/Research\%2D\%2DPolicy/Resource-bank/resources/84/How-internationalised-is-your-university. .

Spencer-Oatey, H., \& Dauber, D. (in press). What is integration and why is it important for internationalisation? A multidisciplinary review. Journal of Studies in International Education.

Spencer-Oatey, H., Dauber, D., Jing, J., \& Wang, L. (2017). Chinese students' social integration in the university community: hearing the students' voices. Higher Education, 74, 739-756. https://doi.org/10.1007/s10734016-0074-0.

Sweeney, A., Weaven, S., \& Herington, C. (2008). Multicultural influences on group learning: a qualitative higher education study. Assessment \& Evaluation in Higher Education, 33(2), 119-132. https://doi. org/10.1080/02602930601125665.

Taylor, E. W. (1994). Intercultural competency: a transformative learning process. Adult Education Quarterly, 44(3), 154-174.

Tinto, V. (1975). Dropout from higher education: a theoretical synthesis of recent research. Review of Educational Research, 45(1), 89-125. 
Tinto, V. (1998). Colleges as communities. Taking research on student persistence seriously. Review of Higher Education, 21(2), 167-177.

UKCOSA. (2004). Broadening our horizons. International students in UK universities and colleges. London. Available at http://institutions.ukcisa.org.uk/Info-for-universities-colleges\%2D\%2Dschools/Publications\%2 D\%2Dresearch/resources/90/Broadening-Our-Horizons-Survey-2004 [Accessed 15 April 2017].

United Nations. (2018). Standard country or area codes for statistical use (M49). New York: United Nations Statistics Division. Retrieved from https://unstats.un.org/unsd/methodology/m49/.

Universities UK International Unit. (2015). International undergraduate students: the UK's competitive advantage. London: The UK HE International Unit. Retrieved from http://www.universitiesuk.ac.uk/policy-andanalysis/reports/Documents/International/international-undergraduate-students-uk-competitive-advantage. pdf.

Universities UK International Unit. (2016). International taught postgraduate students: the UK's competitive advantage. London: The UK HE International Unit. Retrieved from http:/www.universitiesuk.ac.uk/policyand-analysis/reports/Documents/International/international-taught-postgraduate-Students-uk-competitiveadvantage.pdf.

Ward, C. (2001). The impact of international students on domestic students and host institutions: report prepared for the Export Education Policy Project of the New Zealand Ministry of Education, available at https:/www. educationcounts.govt.nz/publications/international/the_impact_of_international_students_on_domestic_ students and host institutions

Ward, C., \& Kennedy, A. (1993). Where's the 'culture' in cross-cultural transition? Comparative studies of sojourner adjustment. Journal of Cross-Cultural Psychology, 24(2), 221-249.

Ward, C., Masgoret, A.-M., Ho, E., Holmes, P., Cooper, J., Newton, J., \& Crabbe, D. (2005). Interactions with international students. Report prepared for Education New Zealand, Centre for Applied Cross-Cultural Research: Victoria University of Wellington. Retrieved from https://www.victoria.ac. $\mathrm{nz} / \mathrm{cacr} /$ documents/New-Zealand-students-perceptions-of-and-interactions-with-international-students-2005Colleen-Ward-et-al.pdf [Accessed 29 December 2017].

Williams, C. T., \& Johnson, L. R. (2011). Why can’t we be friends?: Multicultural attitudes and friendships with international students. International Journal of Intercultural Relations, 35, 41-48.

Zepke, N., \& Leach, L. (2005). Integration and adaptation: approaches to the student retention and achievement puzzle. Active Learning in Higher Education, 6(1), 46-59.

Publisher's note Springer Nature remains neutral with regard to jurisdictional claims in published maps and institutional affiliations. 